\title{
Effect of PGX, a novel functional fibre supplement, on subjective ratings of appetite in overweight and obese women consuming a 3-day structured, low-calorie diet
}

\author{
V Kacinik ${ }^{1}$, M Lyon ${ }^{1,2}$, M Purnama ${ }^{1}$, RA Reimer ${ }^{3}$, R Gahler ${ }^{4}$, TJ Green ${ }^{2}$ and S Wood ${ }^{2,5}$ \\ ${ }^{1}$ Canadian Centre for Functional Medicine, Coquitlam, British Columbia, Canada; ${ }^{2}$ Faculty of Land and Food Systems and \\ Food, Nutrition and Health Program, University of British Columbia, Vancouver, British Columbia, Canada; ${ }^{3}$ Faculty of \\ Kinesiology and Department of Biochemistry and Molecular Biology, University of Calgary, Calgary, Alberta, Canada; \\ ${ }^{4}$ Factors Group Research \& Development, Burnaby, British Columbia, Canada and ${ }^{5}$ InovoBiologic, Calgary, Alberta, Canada
}

Introduction: Dietary factors that help control perceived hunger might improve adherence to calorie-reduced diets.

Objectives: The objective of the study was to investigate the effect of supplementing a three-day, low-calorie diet with PolyGlycopleX (PGX), a highly viscous fibre, on subjective ratings of appetite compared with a placebo.

Methods: In a double-blind crossover design with a 3-week washout, 45 women (aged $38 \pm 9$ years, body mass index $29.9 \pm 2.8 \mathrm{~kg} \mathrm{~m}^{-2}$ ) were randomised to consume a 1000-kcal per day diet for 3 days, supplemented with $5 \mathrm{~g}$ of PGX or placebo at each of breakfast, lunch and dinner. Subjective appetite was assessed using $100 \mathrm{~mm}$ visual analogue scales that were completed daily before, between and after consumption of meals.

Results: Thirty-five women completed the study. Consumption of PGX compared with placebo led to significantly lower mean area under the curve for hunger on day 3 (440.4 versus 375.4; $P=0.048$ ), prospective consumption on day 3 ( 471.0 versus 401.8; $P=0.017$ ) and the overall 3 -day average (468.6 versus $420.2 ; P=0.026$ ). More specifically, on day 3 PGX significantly reduced total appetite, hunger, desire to eat and prospective consumption for 2.5 and $4.5 \mathrm{~h}$ after lunch and before dinner times, with hunger also being reduced $2.5 \mathrm{~h}$ after dinner $(P<0.05)$.

Conclusion: The results show that adding $5 \mathrm{~g}$ of PGX to meals during consumption of a low-calorie diet reduces subjective ratings of prospective consumption and increases the feelings of satiety, especially during afternoon and evening. This highly viscous polysaccharide may be a useful adjunct to weight-loss interventions involving significant caloric reductions.

Nutrition and Diabetes (2011) 1, e22; doi:10.1038/nutd.2011.18; published online 12 December 2011

Keywords: viscous; soluble; fibre; appetite; PGX; PolyGlycopleX

\section{Introduction}

Obesity increases the risk of type 2 diabetes, cardiovascular disease and other chronic diseases. ${ }^{1,2}$ Weight reduction is associated with significant improvements in blood pressure, serum cholesterol levels and glycaemic control. ${ }^{3}$ Achieving negative energy balance is an important factor in determining the magnitude and rate of weight loss. ${ }^{4}$ Calorie-restricted diets, ideally combined with exercise and behaviour modification, are considered to be the initial treatment strategy for overweight and obese individuals. Low-calorie diets at a level of 1000-1200 kcal per day for most overweight women and $1200-1600 \mathrm{kcal}$ per day for most overweight men are

Correspondence: V Kacinik, Canadian Centre for Functional Medicine, 1550 United Boulevard, Coquitlam, British Columbia, Canada V3K6Y2. E-mail: vkacinik@functionalmedicine.ca

Received 6 October 2011; accepted 24 October 2011 often recommended for weight loss. ${ }^{5}$ With low-calorie diets, maintaining satiety is critical, as perceived hunger has been shown to be a significant predictor of failure to lose weight. ${ }^{6}$ After weight loss is achieved, appetite often increases leading to refractory weight gain. ${ }^{7}$ Identifying factors that suppress appetite is important for successful weight loss and maintenance.

Increased fibre intake has been associated with reduced energy intake and increased satiety, and may be an important factor in obesity management. ${ }^{8}$ A meta-analysis of 22 studies concluded that consumption of $14 \mathrm{~g}$ of fibre per day resulted in a $10 \%$ decrease in energy intake and a $1.9-\mathrm{kg}$ weight loss over 3.8 months. ${ }^{9}$ Viscous soluble fibres, in particular, appear to increase satiety ${ }^{10-14}$ and promote adherence to calorie-reduced diets. ${ }^{15,16}$ Accordingly, consuming substantial quantities of viscous dietary fibre may provide significant therapeutic benefits under conditions of reduced energy intake. However, as the benefit of these fibres 
is related to viscosity, ${ }^{17}$ their acceptance is often hampered by issues of palatability. ${ }^{18}$

Recently, PolyGlycopleX (PGX), a novel, highly viscous non-starch polysaccharide complex has been developed for human consumption. This soluble dietary fibre displays delayed viscosity for 15-30 min after ingestion, thus, allowing for a more palatable and easy-to-use functional fibre. In a recent randomised, placebo-controlled trial, PGX was shown to diminish hunger and reduce ad libitum food consumption compared with less viscous fibres (cellulose and glucomannan) given in meal-replacement drinks. ${ }^{19}$ The objective of this study was to investigate the effect of supplementing a three-day low-calorie diet with PGX on subjective ratings of appetite compared with a placebo in overweight and obese women.

\section{Materials and methods}

\section{Subjects}

Subjects were recruited through local newspaper advertisements. Women with a body mass index between 25 and $34.9 \mathrm{~kg} \mathrm{~m}^{-2}$ and between 20 and 50 years of age were eligible to participate. Exclusion criteria included: pregnancy or lactation, smoking, consumption of more than two alcoholic drinks daily or nine alcoholic drinks weekly, recent participation in a calorie-reduced diet, the presence of chronic diseases, past history of gastrointestinal surgery, a change in body weight of more than $3 \mathrm{~kg}$ during the last 3 months, hypersensitivity to the study foods, taking medication or natural health products, which may affect gastrointestinal motility hunger or appetite. Furthermore excluded were those who scored 9 or more on the restraint scale; 27 or above for uncontrolled eating, or 18 or greater for emotional eating on the Three-Factor Eating Questionnaire-R18V2, validated for Canadian and US obese and non-obese individuals. ${ }^{20}$ As lower palatability of foods may diminish the sensation of hunger and desire to eat, ${ }^{21}$ a Food Preference Questionnaire was used to ensure that all the participants expressed acceptance of the foods included in the study. Those scoring less than 3 for more than $50 \%$ of the food items were excluded from the study. The University of British Columbia Research Ethics Committee approved the study and all subjects gave informed consent to participate.

\section{Study supplements}

PGX ( $\alpha$-D-glucurono- $\alpha$-D-manno- $\beta$-D-manno- $\beta$-D-gluco), $(\alpha-\mathrm{L}-$ gulurono- $\beta$-D mannurono), $\beta$-D-gluco- $\beta$-D-mannan (Inovobiologic, Calgary, Alberta, Canada) is a novel functional fibre complex ${ }^{22,23}$ manufactured by a proprietary process from three fibres (konjac (glucomannan), sodium alginate and xanthan gum) to form a highly viscous polysaccharide (higher viscosity than any currently known individual polysaccharide or fibre blend) with high water-holding and gel-forming properties. PGX has been shown to be safe and well tolerated in rodents ${ }^{24}$ and in humans. ${ }^{25}$ Genotoxicity studies of PGX have shown no mutagenic effects using bacterial reverse mutation and mouse micronucleus assays. ${ }^{26}$ PGX is $87.4 \%$ dietary fibre, of which $81.8 \%$ is soluble. It can be sprinkled on food before consumption or taken with soup or beverage before meals. Rice flour was used as a placebo and has been used in other clinical trials for its white colour, neutral taste and hypoallergenicity. ${ }^{27,28}$ PGX and rice flour both consist of approximately similar carbohydrate content with carbohydrate in PGX being dietary fibre and in rice flour being starch. Boiling or other forms of moist heat processing is required for rice flour to be effectively digested. Without cooking, only about $1 \%$ of the starch in raw rice flour is digested. ${ }^{29}$ Therefore, the carbohydrate in uncooked rice flour is essentially dietary fibre resulting in rice flour's caloric value that closely approximates PGX. Both study supplements were packaged with clear plastic scoops in white plastic containers containing $100 \mathrm{~g}$ and were indistinguishable from each other.

\section{Study design/protocol}

The study was a prospective, randomised, double-blind, placebo-controlled crossover trial. The study had two experimental phases with a 3-week washout. Test periods were on the same days of the week (Tuesday-Thursday) and were conducted during the follicular phase (days 4-10) of the women's menstrual cycle to minimise hormonal influences on eating/feeding behaviour and appetite. ${ }^{30}$ On Monday of the test week, subjects attended the clinic where their bodyweight was measured, study food was provided and they were randomised to either the test or placebo supplement. During the test period, subjects consumed the breakfasts, lunches and dinners provided immediately after the food was sprinkled with $5 \mathrm{~g}$ of supplement or placebo. Participants completed visual analogue scales (VAS) questionnaires at specified times (see below). To avoid a second meal effect and to minimise differences in glycogen stores, the night before consumption of the 3-day low-calorie diet, all subjects consumed the same evening meal. In addition, participants were instructed not to consume alcohol or engage in vigorous physical activity $48 \mathrm{~h}$ before consuming the low-calorie diet. On Friday, subjects returned to the clinic to have their compliance assessed, documents reviewed and to have any adverse effects recorded. To assess compliance, subjects kept a log of daily food and study product consumed and returned the product containers for weighing.

\section{Low-calorie diet}

A three-day structured low-calorie diet of $1000 \mathrm{kcal}$ per day was provided with the intention that caloric restriction would accentuate feelings of hunger. The low-calorie diet was designed to provide participants with $65 \%$ of energy as carbohydrate, $10 \%$ protein, and $15 \%$ fat (Appendix 1). Commercially available frozen dinner entrees (President's 
Choice Blue Menu, Loblaw, Ontario, Canada) were provided to participants to standardise caloric intake and macronutrient composition.

\section{Subjective appetite measures}

Rating subjective appetite using VAS is a valid and reliable measure of appetite under both experimental and free-living conditions, especially when using a within-subject design, as used in the current study. ${ }^{31,32}$ VAS ratings were made on a $100-\mathrm{mm}$ scale with words anchored at either end in the following order: first, 'How strong is your desire to eat?' (Very strong - Very weak); second, 'How hungry do you feel?' (Not hungry at all-Very hungry); third, 'How full do you feel?' (Very full-Not at all full); and fourth, 'How much food do you think you could eat?' (A large amount-Nothing at all), which assesses prospective consumption. The palatability of the meals was also evaluated after meals by a fifth question asking 'How would you rate the overall palatability of the food? (Unpalatable - Very palatable). The times of rating were the same every day for both phases; however, to work with participants at various schedules, different start times in the morning were available. VAS were completed before (e.g., $0755 \mathrm{~h}$ ) and after breakfast (e.g., $0830 \mathrm{~h}$ ), in between the morning meals (e.g., $1030 \mathrm{~h}$ ), before (e.g., $1225 \mathrm{~h}$ ) and after (e.g., $1300 \mathrm{~h}$ ) lunch, in between meals in the afternoon (e.g., $1500 \mathrm{~h}, 1700 \mathrm{~h}$ ), before (e.g., $1725 \mathrm{~h}$ ) and after (e.g., $1800 \mathrm{~h}$ ) dinner and in the evening (e.g., $2000 \mathrm{~h}$ ). Participants were provided with programmable alert wrist watches (CADEX Medication reminder watch, e-pill, LLC., Wellesley, MA, USA) to remind them when to eat and when to complete the questionnaires. Participants were allowed $20 \mathrm{~min}$ to consume the food, supplement and $500 \mathrm{ml}$ of water, and were allowed to consume an additional $500 \mathrm{ml}$ of water between meals. Participants were instructed not to consume water $30 \mathrm{~min}$ before completing premeal VAS. All food and water consumed during Phase 1 was recorded and the same amount was provided for Phase 2 .

\section{Statistical analyses}

Changes in weight over each test period were tested for differences between treatment groups using the Wilcoxon rank sum test. For compliance, the $P$-values of differences between the two treatment groups within a single period were calculated from two-sample $t$-tests; the statistical test for the summary across both periods of data used a linear mixed model approach, which took into consideration that the same participants appeared once on each of the two treatments (due to the crossover design). For VAS score analyses, the area under the curve was analysed on the log scale to meet the distributional assumptions required for the statistical methods. The treatment effect was estimated from a linear mixed-effects model to take into consideration the crossover design of the study; the model was adjusted for phase, treatment, randomised sequence and a within-patient comparison was made to assess the treatment effect. With

the different study days expected to give differences in results, the analysis was carried out by days $1,2,3$ and on the mean of days $1-3$. To analyse VAS scores by time point, a similar linear mixed model was used incorporating terms in the model for treatment, phase, randomised group and time point, and then contrasts used to compare the treatment groups at the different time points. Statistical testing of the adverse event rates by treatment (either overall rates, treatment-related rates or rates for specific types of adverse events) was performed using generalised estimating equations logistic regression models. To evaluate whether there was a carryover effect in the second period by the randomised sequences, a standard statistical approach by Jones et al. ${ }^{33}$ was used to assess. For all statistical tests, the significance level was set at 0.05 . All analyses were performed using SAS (Version 9.1.3, SAS Institute, Cary, NC, USA).

\section{Results}

In total, 51 individuals were recruited for the study of which 45 were randomised (Table 1). After Phase 1, five discontinued from the study. The reasons for withdrawal were adverse events $(n=2)$, dislike of the frozen meals offered $(n=1)$ and personal reasons unrelated to the study $(n=2)$. Overall, 40 participants completed the entire study; however, only 35 participants were included in the per-protocol analyses as 2 participants deviated from the protocol and 3 reported feeling sick, which might affect subjective appetite ratings. Compliance was high for both groups, with $107 \%$ and $97 \%$ for the rice flour and PGX groups, respectively. There was no carryover effect in the second period by the randomised sequences.

Weight loss was similar between groups over the two phases (PGX $1.3 \mathrm{~kg}$ versus placebo $1.4 \mathrm{~kg} ; P=0.376$ ). From the intent-to-treat analysis $(n=40)$, the PGX treatment resulted in a significantly lower mean area under the curve

Table 1 Subject characteristics

\begin{tabular}{|c|c|}
\hline & Value (range) \\
\hline Age (years) & $38.6 \pm 9.1(20-50)$ \\
\hline Weight (kg) & $79.8 \pm 9.3(59.4-107.8)$ \\
\hline Body mass index $\left(\mathrm{kg} \mathrm{m}^{-2}\right)$ & $29.9 \pm 2.8(25.0-34.8)$ \\
\hline Waist circumference $(\mathrm{cm})$ & $87.0 \pm 7.4(73.3-106.0)$ \\
\hline \multicolumn{2}{|c|}{ Three-factor eating questionnaire ${ }^{a}$} \\
\hline Cognitive & $7.3 \pm 3.1(4.0-25.0)$ \\
\hline Uncontrolled eating & $21.2 \pm 4.6(5.0-27.0)$ \\
\hline Emotional eating & $14.3 \pm 3.8(7.0-24.0)$ \\
\hline \multicolumn{2}{|c|}{$\begin{array}{l}\text { Values are mean } \pm \text { s.d.; } n=45 \text {. }{ }^{a} \text { The Three-Factor Eating Questionnaire } \\
\text { evaluates some aspects of eating behaviours such as cognitive restraint } \\
\text { (i.e., the voluntary control of eating), the tendency to lose control of food } \\
\text { intake when faced with external cues, mood changes or disruptive events } \\
\text { (i.e., disinhibition) and susceptibility to feelings of hunger. In this study, the } \\
\text { Three-Factor Eating-R } 18 \mathrm{~V} 2 \text { questionnaire was used as a means to exclude } \\
\text { those who have potentially disordered eating motivation and to assess } \\
\text { motivation of the participants eligible for the study. }{ }^{20}\end{array}$} \\
\hline
\end{tabular}


on day 3 for prospective consumption $(P=0.018)$ and a trend towards significance for hunger $(P=0.059)$. After elimination of the protocol deviators $(n=35)$, a similar pattern was seen with the differences between groups stronger with a mean percent change of prospective consumption at $-14.7(P=0.017)$ and hunger at -14.8 on day $3(P=0.048$, Table 2$)$. There were no statistical differences in mean area under the curve for any of the scores for day 1 or 2 , or the mean days $1-3$, except for prospective consumption $(P=0.026)$. The majority of differences in subjective ratings between the placebo and PGX groups at various time points were detected on day 3. PGX supplementation significantly reduced total appetite, desire to eat, hunger, prospective consumption, and it was associated with increased fullness at $2.5 \mathrm{~h}$ after lunch (Figure 1); reduced total appetite, desire to eat, hunger and prospective consumption at $4.5 \mathrm{~h}$ after lunch (Figure 2) and reduced total appetite, hunger and prospective consumption before dinner (Figure 3). Hunger was also reduced at $2.5 \mathrm{~h}$ after dinner $(P<0.05)$. For palatability, there was a statistically significant difference in mean palatability VAS scores by treatment for each day $(P<0.05)$, with PGX'supplemented meals scoring above $50 \mathrm{~mm}$, but $5-10 \mathrm{~mm}$ below mean rice flour scores (data not shown).

Adverse events reported by both treatment groups are summarised in Table 3 . There was no statistical difference between the two treatment groups in terms of the adverse events experience of the participants. Furthermore, the overall or treatment-related adverse events were similar for the two treatments.

\section{Discussion}

This study demonstrates that adding $5 \mathrm{~g}$ of PGX to meals at the start of a low-calorie diet helps manage appetite by increasing satiety and decreasing prospective consumption (the amount one thinks one could eat). This effect was not statistically significant until day 3; however it resulted in reductions above $10 \%$ compared with the control, a

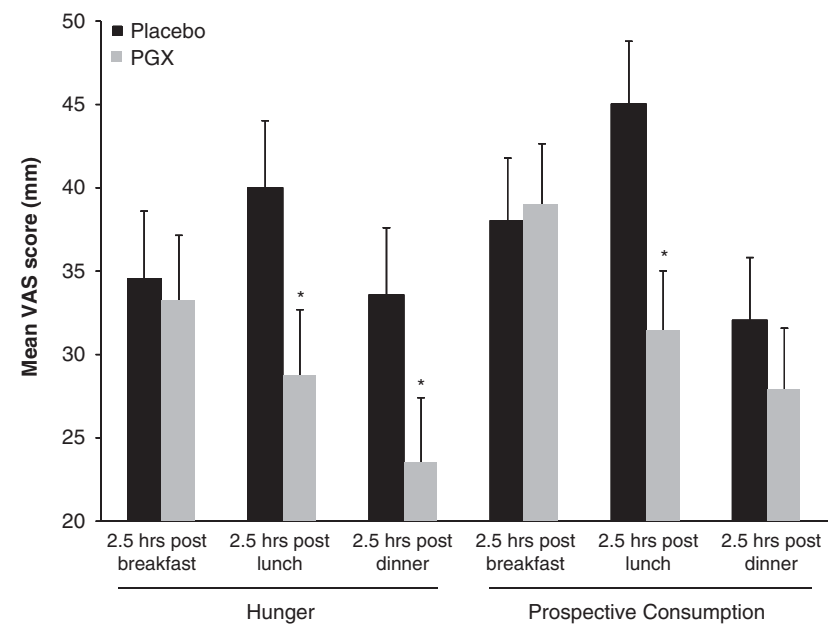

Figure 1 Comparison of $2.5 \mathrm{~h}$ post breakfast, lunch and dinner mean hunger and prospective consumption scores of day 3 of the 1000-kcal calorie diet supplement with either $5 \mathrm{~g}$ of PGX or placebo at each meal. Values shown are mean \pm s.e. $(n=35)$. *Significantly lower scores with PGX than with the placebo supplement $(P<0.05)$.

Table 2 Daily and 3-day average comparison of subjective appetite measurements calculated as mean area under the curve in response to placebo or PGX for the per-protocol subject group

\begin{tabular}{|c|c|c|c|c|c|}
\hline Score & Day & Placebo & $P G X$ & \% Change & P-value \\
\hline \multirow{4}{*}{ Prospective consumption } & 1 & $457.2 \pm 29.4$ & $432.5 \pm 27.8$ & -5.4 & 0.358 \\
\hline & 2 & $477.9 \pm 33.1$ & $427.1 \pm 29.6$ & -10.6 & 0.079 \\
\hline & 3 & $471 \pm 32.5$ & $401.8 \pm 27.7$ & -14.7 & 0.017 \\
\hline & Average days 1-3 & $468.6 \pm 28.9$ & $420.2 \pm 25.9$ & -10.3 & 0.026 \\
\hline \multirow[t]{4}{*}{ Desire } & 1 & $432.5 \pm 29.4$ & $428.8 \pm 29.1$ & -0.9 & 0.894 \\
\hline & 2 & $456.3 \pm 34.2$ & $416.9 \pm 31.3$ & -8.6 & 0.273 \\
\hline & 3 & $427.7 \pm 35$ & $387.9 \pm 31.7$ & -9.3 & 0.280 \\
\hline & Average days 1-3 & $438.6 \pm 29.7$ & $410.8 \pm 27.8$ & -6.3 & 0.303 \\
\hline \multirow[t]{4}{*}{ Fullness } & 1 & $598.3 \pm 40.3$ & $591.6 \pm 39.9$ & -1.1 & 0.832 \\
\hline & 2 & $584.5 \pm 50.7$ & $574.5 \pm 49.8$ & -1.7 & 0.785 \\
\hline & 3 & $614.1 \pm 47.2$ & $632.3 \pm 48.6$ & 3 & 0.592 \\
\hline & Average days $1-3$ & $598.8 \pm 43.8$ & $599 \pm 43.9$ & 0 & 0.996 \\
\hline \multirow[t]{4}{*}{ Hunger } & 1 & $431.5 \pm 28.6$ & $418.3 \pm 27.7$ & -3.1 & 0.651 \\
\hline & 2 & $434.9 \pm 33.6$ & $407.6 \pm 31.5$ & -6.3 & 0.429 \\
\hline & 3 & $440.4 \pm 32.9$ & $375.4 \pm 28$ & -14.8 & 0.048 \\
\hline & Average days $1-3$ & $435.6 \pm 28.4$ & $400 \pm 26.1$ & -8.2 & 0.162 \\
\hline \multirow[t]{4}{*}{ Total appetite } & 1 & $469.8 \pm 27.3$ & $458.7 \pm 26.7$ & -2.4 & 0.675 \\
\hline & 2 & $475.9 \pm 31.8$ & $449.4 \pm 30.0$ & -5.6 & 0.390 \\
\hline & 3 & $464.5 \pm 31.9$ & $414.3 \pm 28.4$ & -10.8 & 0.106 \\
\hline & Average days 1-3 & $470 \pm 27.9$ & $440.4 \pm 26.2$ & -6.3 & 0.215 \\
\hline
\end{tabular}

Abbreviation: PGX, PolyGlycopleX. Note: $P$-value is from a linear mixed-model fit on log scale of area under curve and adjusting for potential sequence and period effects in addition to treatment (significance level $P<0.05$ ). Values shown are mean \pm s.e.; $n=35$. 


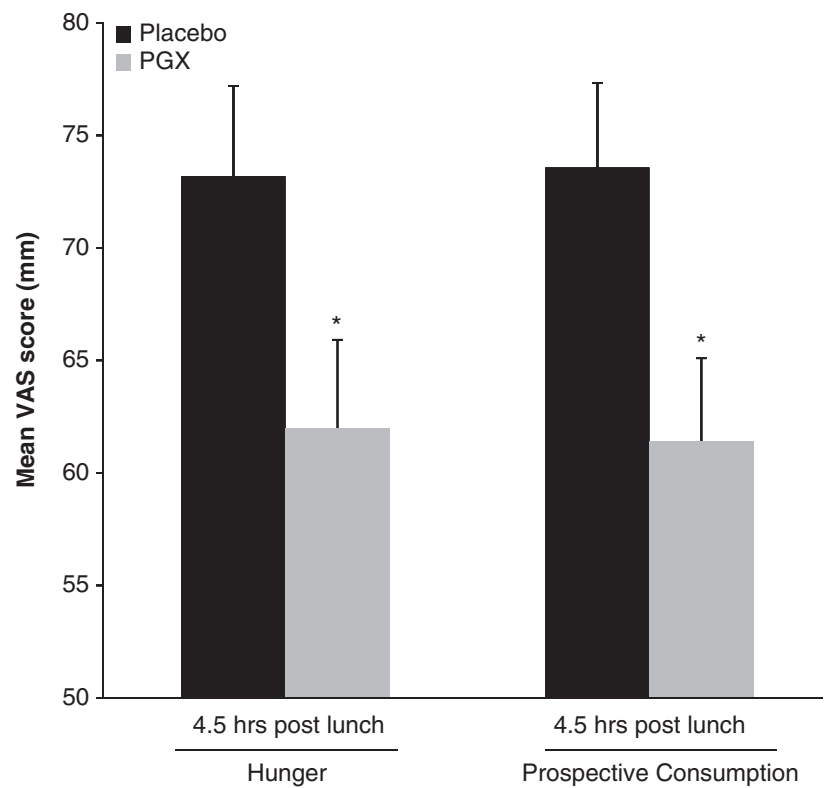

Figure 2 Comparison of the $4.5 \mathrm{~h}$ post lunch mean hunger and prospective consumption scores of day 3 of the $1000-\mathrm{kcal}$ calorie diet supplement with either $5 \mathrm{~g}$ of PGX or placebo at each meal. Values shown are mean \pm s.e. $(n=35)$. *Significantly lower scores with PGX than with the placebo supplement $(P<0.05)$

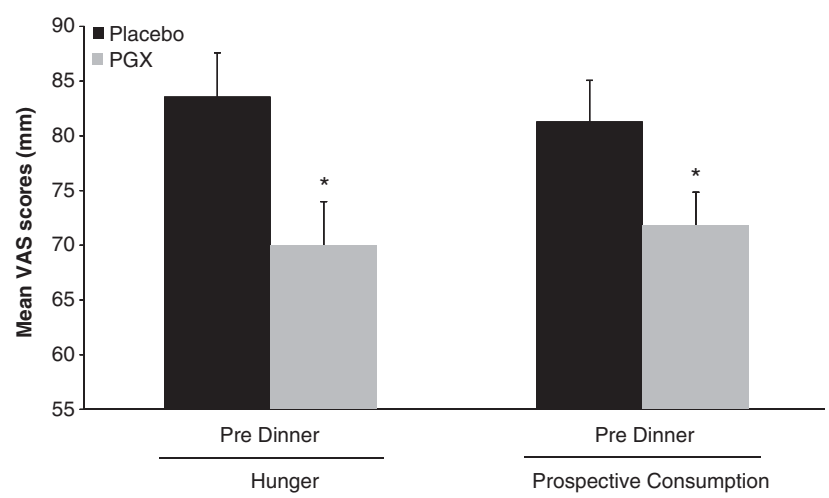

Figure 3 Comparison of predinner mean hunger and prospective consumption scores of day 3 of the $1000-\mathrm{kcal}$ calorie diet supplement with either $5 \mathrm{~g}$ of PGX or placebo at each meal. Values shown are mean \pm s.e. $(n=35)$. *Significantly lower scores with PGX than with the placebo supplement $(P<0.05)$

magnitude which is considered to be of practical relevance. ${ }^{32}$ With respect to time of day, PGX was found to exert its strongest effects in the afternoon and in the evening, reducing total appetite, hunger, desire to eat and prospective consumption. These results might be particularly helpful in managing obesity, given reports that food intake tends to be less in the morning and greater in the afternoon and highly evening in obese versus normal weight individuals. ${ }^{34}$ One explanation for the effect seen with PGX on day 3 could be the increased fibre load. This particular test day had $7 \mathrm{~g}$ more dietary fibre and 9$10 \mathrm{~g}$ less protein than on day 1 or 2 , resulting in a possible synergistic effect and interaction between the PGX and the dietary fibre content of the meals. Another possibility may be the cumulative effects of PGX over time with the potential for upregulation of gut-satiety hormone gene expression (such as proglucagon) via fermentation and production of short-chain fatty acids in the large bowel. ${ }^{35}$

Soluble fibres that are fermentable by gut microbiota and produce significant quantities of short-chain fatty acids may contribute to appetite regulation by stimulating the release of gut-satiety hormones such as peptide YY (PYY) and glucagon like peptide-1. ${ }^{36}$ In a study using Zucker diabetic rats, PGX consumption was associated with a significant increase in glucagon like peptide- 1 levels. ${ }^{37}$ In a 3-week human tolerance trial, supplementation of regular diets with $10 \mathrm{~g}$ of PGX per day was associated with higher fasting PYY levels than placebo control. ${ }^{38}$ It has been reported that obese individuals have lower fasting and postprandial circulating PYY levels than lean individuals, ${ }^{39,40}$ which may result in impaired satiety and may contribute to the development of obesity and may hinder weight loss efforts. To produce an equivalent stimulation of PYY sufficient to promote satiety, obese individuals need to consume a much greater caloric load than their lean counterparts. ${ }^{39}$ An alternative to a greater caloric load could be a volumetric, lower energy dense load from supplementing a meal with PGX to augment PYY levels and stimulate satiety. Further investigation of a low-calorie diet supplemented with PGX on gut-satiety hormones is thus warranted.

Under conditions of fixed energy intake, such as a lowcalorie diet, viscous soluble fibres may also alter the viscosity of gastrointestinal content resulting in multiple effects on satiety. A magnetic resonance imaging study by Marciani et $a l .{ }^{41}$ showed that a high-viscosity nutrient meal had the strongest additive effect in gastric distension and delayed gastric emptying compared with low-viscosity non-nutrient, low-viscosity nutrient and high-viscosity non-nutrient meals. Viscous soluble fibres also delay the absorption of nutrients by thickening the unstirred layer at the gut mucosal surface. This results in the transport of larger amounts of nutrients to the ileum and/or distributes nutrient absorption over a larger intestinal luminal surface area, leading to a more pronounced inhibitory feedback from the distal gut and activation of the ileal brake. ${ }^{42}$ Other mediators of the ileal brake include the gut-satiety hormones PYY and glucagon like peptide-1 and vagal nerve stimulation. ${ }^{43}$ The ileal brake is a distal to proximal negative feedback mechanism that inhibits gastric emptying, proximal gastrointestinal motility and secretion to control the transit of a meal through the gastrointestinal tract, which consequently optimises nutrient digestion and absorption. ${ }^{44}$

As a highly viscous soluble fibre, PGX may cause a delay in gastric emptying and/or prolong the transport of nutrients down the gastrointestinal tract as demonstrated by previous research on its effects on the glycaemic index (GI). The GI is a property of carbohydrate-containing food that describes the rise of blood glucose occurring after a meal. High GI 
Table 3 Summary of the adverse events (AEs) by treatment allocation

\begin{tabular}{|c|c|c|c|c|}
\hline Variable & & Placebo & $P G X$ & P-value \\
\hline Number of participants & & 38 & 42 & \\
\hline Participants reporting adverse events & & $13(34.2 \%)$ & $12(28.6 \%)$ & 0.7 \\
\hline Total adverse events & & 25 & 28 & \\
\hline Participants reporting treatment-related events & & $8(21.1 \%)$ & $11(26.2 \%)$ & 0.34 \\
\hline Total treatment-related Events & & 19 & 24 & \\
\hline \multirow[t]{4}{*}{ Total adverse events (by severity) } & Unknown severity & 0 & 0 & \\
\hline & Mild & 5 & 2 & \\
\hline & Moderate & 13 & 21 & \\
\hline & Severe & 7 & 5 & \\
\hline \multirow[t]{4}{*}{ Total treatment-related events (by severity) } & Unknown Severity & 0 & 0 & \\
\hline & Mild & 4 & 2 & \\
\hline & Moderate & 9 & 18 & \\
\hline & Severe & 6 & 4 & \\
\hline \multirow[t]{8}{*}{ Participants reporting AEs by type of $\mathrm{AE}$} & Constipation & $3(7.9 \%)$ & $1(2.4 \%)$ & 0.15 \\
\hline & Diarrhea & $0(0.0 \%)$ & $3(7.1 \%)$ & NA \\
\hline & Bloating & $4(10.5 \%)$ & $8(19 \%)$ & 0.07 \\
\hline & Flatulence & $0(0.0 \%)$ & $2(4.8 \%)$ & NA \\
\hline & Headache & $4(10.5 \%)$ & $1(2.4 \%)$ & 0.17 \\
\hline & Cramping & $3(7.9 \%)$ & $3(7.1 \%)$ & 0.59 \\
\hline & Sick/unwell & $4(10.5 \%)$ & $1(2.4 \%)$ & 0.08 \\
\hline & Other & $3(7.9 \%)$ & $7(16.7 \%)$ & 0.06 \\
\hline
\end{tabular}

Abbreviation: PGX, PolyGlycopleX. Parentheses denote the percentage from the total number of participants. Some $P$-values were not possible to compute due to no events being reported under one of the treatment groups. These are noted as ' $N A$ ' in the table.

foods are classified as being rapidly digested and absorbed into the bloodstream, resulting in a sharp rise and in a steep decline of blood glucose after consumption, whereas low GI foods are broken down more slowly by a slower rate of digestion and absorption and releasing glucose more gradually into the bloodstream. ${ }^{45}$ When $2.5-5 \mathrm{~g}$ of PGX was sprinkled on high and moderate GI foods, it was consistently shown to be highly effective in significantly reducing their glycaemic index. ${ }^{4,46}$ Influencing the digestive rate of foods and their blood glucose response may have an important effect on the perception of satiety. Arumugam et al. ${ }^{47}$ examined the effects of high-GI versus low-GI meals on subjective satiety in overweight and obese women. They found that the appetite score was 35\% higher at $4 \mathrm{~h}$ after the high-glycaemic versus low glycaemic breakfast, and that at 3 , 4 and $5 \mathrm{~h}$ after lunch, the appetite score was 30-44\% higher in the high glycaemic condition. ${ }^{47}$ Many other short-term studies ( $<1$ day) have also reported a significant relationship between the glycaemic response and satiety using foods with varying glycaemic indices. ${ }^{48-51}$ In the present study, the frozen meals were chosen to represent the average Western diet with convenient, processed higher GI foods and as such the effect of PGX supplementation on the study foods' glycaemic indices might be related to the $28 \%, 14 \%, 12 \%$ reduction of total appetite score at $2.5,4.5,5 \mathrm{~h}$, respectively, after consuming the lunch on day 3 . If however the study foods had a low GI, PGX may not have exerted as significant an effect on satiety.

This study was designed to alleviate some potentially confounding variables in appetite research. The timing of the test phases was scheduled according to participants' menstrual cycle, given that previous research has linked changes in gastrointestinal function, appetite and energy intake to the follicular and luteal phases of menstruation. ${ }^{30}$ The energy intake, macronutrient composition, water consumption and eating schedule for all the meals over the three-diet days were controlled, demonstrating the effect of PGX on homeostatic hunger (physiological). Although the effect of PGX on ad libitum food intake cannot be concluded, prior research has shown that subjective ratings of appetite appear to be good indicators of motivation to eat and are predictors of actual food intake. $^{31,52,53}$ However, it should also be mentioned that appetite ratings have not always been found to correlate with ad libitum food intake, ${ }^{10}$ as many factors influence food intake, including sensory hedonics, external factors, cognitive issues, body weight, genes and so on. ${ }^{54-56}$

To minimise the effect of palatability on appetite ratings, women who rated the palatability of the meals low were excluded. However, a significant difference in palatability between meals supplemented with PGX and rice flour was observed on all of the three-diet days. Previous research with PGX has not found any significant differences in palatability scores in comparisons with controls. ${ }^{19,45}$ Study participants were advised to sprinkle PGX granules as they ate; however, the hot microwaved meals for lunch and dinner more than likely accelerated viscosity development, thereby affecting texture and palatability. This difference may be related more to texture than to any gastrointestinal discomforts experienced with PGX, as there was no statistical difference in adverse events reported between PGX and rice flour. Although palatability affects appetite, ${ }^{57,58}$ this did not translate into significant differences in subjective appetite 
scores for days 1 and 2, suggesting that the difference observed on day 3 may have not been due to the palatability of the PGX'supplemented meal. When designing placebocontrolled trials with PGX, it is difficult to find a comparable inert substance and completely avoid any potentially confounding effect. Uncooked rice flour was found to closely approximate PGX in terms of flavour and texture, and it was thus judged to be a suitable placebo. However, the presence of resistant starches may have produced an increase in fermentation in the control group and dampened the difference in results between the two interventions.

As an initial investigation, this study was performed over 3 days because of the number of VAS questionnaires dispensed and strict adherence required for the food and meal schedule. It was conducted under free-living conditions so as to mimic people following a structured low-calorie diet in their regular lives. However, this inherently introduced some variability in the participants' environment, occupational and non-occupational activities, which could have resulted in diurnal variations in appetite. ${ }^{59}$ Furthermore, the diet during the two test phases was self-administered and even though compliance of the study supplements was high, the possibility of noncompliance with the prescribed diets could not be completely avoided.

In summary, this study indicates that the supplementation of highly viscous PGX to meals could be a useful weight management aid during a low-calorie diet to help lessen feelings of hunger and to moderate food portions. Weight relapse after consuming a low-calorie diet is a common outcome of obesity interventions. Therefore, long-term studies investigating the effects of PGX on subjective appetite and the maintenance of reduced body weight would be warranted. In addition, it would be useful to examine the effects of PGX on biomarkers such as glucagon like peptide-1, PYY and ghrelin to better understand some of the physiological influences of PGX on satiety. By virtue of its multiple physiological effects on the mechanisms of satiety, PGX may be an effective weightmanagement aid for low-calorie diets.

\section{Conflict of interest}

VK and MP are employees of the Canadian Centre for Functional Medicine where the study took place. ML is a consultant to the parent company of the sponsor. TG, RAR and SW receive consulting fees from InovoBiologic. RG is the owner of the Factors Group of Nutritional Companies and retains an interest in PGX. PGX, PolyGlycopleX are trademarks of InovoBiologic. All other marks are the property of their respective owners.

\section{Acknowledgements}

We wish to thank the efforts of Ms Tracey Wood and Ms Suzana Damjanovic, whose support and organisational expertise were invaluable during the completion of this study, and Dr Natalie Kacinik for editorial assistance in the completion of this manuscript. We would also like to acknowledge support of the study and supply of PGX by InovoBiologic.

\section{References}

1 Flegal KM, Graubard BI, Williamson DF, Gail MH. Excess deaths associated with underweight, overweight, and obesity. JAMA 2005; 293: 1861-1867.

2 Gregg EW, Cheng YJ, Cadwell BL, Imperatore G, Williams DE, Flegal $\mathrm{KM}$ et al. Secular trends in cardiovascular disease risk factors according to body mass index in US adults. JAMA 2005; 293: 1868-1874.

3 Blackburn GL. Effect of degree of weight loss on health benefits. Obes Res 1995; 3: 211S-216S.

4 Hill JO. Understanding and addressing the epidemic of obesity: an energy balance perspective. Endocr Rev 2006; 27: 750-761.

5 National Heart, Lung, and Blood Institute Expert Panel on the Identification, Evaluation, and Treatment of Overweight and Obesity in Adults. Executive summary of the clinical guidelines on the identification, evaluation, and treatment of overweight and obesity in adults. Arch Intern Med 1998; 158: 1855-1867.

6 Womble LG, Williamson DA, Greenway FL, Redmann SM. Psychological and behavioural predictors of weight loss during drug treatment for obesity. Int J Obes Relat Metab 2001; 25: 340-345.

7 Doucet E, St-Pierre S, Almeras N, Tremblay A. Relation between appetite ratings before and after a standard meal and estimates of daily energy intake in obese and reduced obese individuals. Appetite 2003; 40: 137-143.

8 Delzenne NM, Cani PD. A place for dietary fiber in the management of the metabolic syndrome. Curr Opin Clin Nutr Metab Care 2005; 8: 636-640.

9 Howarth NC, Saltzman E, Roberts SB. Dietary fiber and weight regulation. Nutr Rev 2001; 59: 129-139.

10 Wanders AJ, van den Borne JJGC, de Graff C, Hulshof T, Jonathan MC, Kristensen $\mathrm{M}$ et al. Effects of dietary fibre on subjective appetite, energy intake and body weight: a systematic review of randomized controlled trial. Obes Rev 2011; 12: 724-739.

11 Mattes RD, Rothacker D. Beverage viscosity is inversely related to postprandial hunger in humans. Physiol Behavior 2001; 74: 551-557.

12 Delargy HJ, Burley VJ, O'Sullivan KR, Fletcher RJ, Blundell JE. Effects of different soluble: insoluble fiber ratios at breakfast on 24-h pattern of dietary intake and satiety. Eur J Clin Nutr 1995; 49: 754-766.

13 Delargy HJ, O'Sullivan KR, Fletcher RJ, Blundell JE. Effects of the amount and type of dietary fiber (soluble and insoluble) on short term control of appetite. Int J Food Sci Nutr 1997; 48: 67-77.

14 Chow JM, Choe YS, Noss MJ, Robinson KJ, Dugle JE, Acosta SH et al. Effect of a viscous fiber-containing nutrition bar on satiety of patients with type 2 diabetes. Diabetes Res Clin Pract 2007; 76: 335-340.

15 Astrup A, Vrist E, Quaade F. Dietary fiber added to very low calorie diet reduces hunger and alleviates constipation. Int J Obes 1990; 14: 105-112.

16 Pasman WJ, Saris WHM, Wauters MAJ, Westerterp-Plantenga MS Effect of one week fiber supplementation on hunger and satiety ratings and energy intake. Appetite 1997; 29: 77-87.

17 Jenkins DJ, Wolever TM, Leeds AR, Gassull MA, Haisman P, Dilawari J et al. Dietary fibers, fiber analogues, and glucose tolerance: importance of viscosity. Br Med J 1978; 1: 1392-1394.

18 Ellis PR, Apling EC, Leeds AR, Bolster NR. Guar bread: acceptability and efficacy combined. Studies on blood glucose, serum insulin and satiety in normal subjects. Br J Nutr 1981; 46: 267-276.

19 Vuksan V, Panahi S, Lyon M, Rogovik A, Jenkins A, Leiter L. Viscosity of fiber preloads affects food intake in adolescents. Nutr Metab Cardiovasc Dis 2009; 19: 498-503.

20 Cappelleri JC, Bushmakin AG, Gerber RA, Leidy NK, Sexton CC, Lowe MR et al. Psychometric analysis off the three-factor eating 
questionnaire-R21: results from a large diverse sample of obese and non-obese participants. Int J Obes 2009; 33: 611-620.

21 Blundell JE, Burley VJ. Satiation, satiety and the action of fiber on food intake. Int J Obes 1987; 11: 9-25.

22 Abdelhameed AS, Ang A, Morris GA, Smith I, Lawson C, Gahler R et al. An analytical ultracentrifuge study on ternary mixtures of konjac glucomannan supplemented with sodium alginate and xanthan gum. Carbohydr Polym 2010; 81: 141-148.

23 Harding SE, Smith IH, Lawson CJ, Gahler RJ, Wood S. Studies on macromolecular interactions in ternary mixtures of konjac glucomannan, xanthan gum and sodium alginate. J Carbpol 2010; 10: 1016-1020.

24 Matulka R, Lyon M, Wood S, Marone P, Merkel D, Burdock G. The safety of PolyGlycopleX ${ }^{\circledR}\left(\mathrm{PGX}^{\circledR}\right)$ as shown in a 90-day rodent feeding study. Nutr J 2009; 8: 1-11.

25 Carabin I, Lyon M, Wood S, Pelletier X, Donazzolo Y, Burdock G. Supplementation of the diet with the functional fiber PolyGlycoplex $^{\circledR}$ is well tolerated by healthy subjects in a clinical trial. Nutr J 2009; 8: 9.

26 Marone P, Lyon M, Gahler R, Donath C, Hofman-Huther H, Wood S. Genotoxicity studies of PolyGlycopleX ${ }^{\circledR}\left(\mathrm{PGX}^{\circledR}\right)$ : a novel dietary fiber. Int J Toxicol 2009; 28: 318-331.

27 Boon H, Clitheroe J, Forte T. Effects of greens $+{ }^{\mathbb{R}}$ : a randomized, controlled trial. Can J Diet Prac Res 2004; 65: 66-71.

28 Bijkerk CJ, de Wit NJ, Muris JWM, Whorwell PJ, Knottnerus JA, Hoes AW. Soluble or insoluble fiber in irritable bowel syndrome in primary care? Randomised placebo controlled trial. Br Med J 2009; 339: b.3154.

29 Niba LL. Processing effects on susceptibility of starch to digestion in some dietary starch sources. Int J Food Sci Nutr 2003; 54: 97-109.

30 Brennan IM, Feltrin KL, Nair NS, Hausken T, Little TJ, Gentilcore $\mathrm{D}$ et al. Effects of the phases of the menstrual cycle on gastric emptying, glycemia, plasma GLP-1 and insulin, and energy intake in healthy lean women. Am J Physiol Gastrointest Liver Physiol 2009; 297: G602-G610.

31 Stubbs RJ, Hughes DAQ, Johnstone AM, Rowley E, Reid C, Elia M et al. The use of visual analogue scales to assess motivation to eat in human subjects: a review of their reliability and validity with an evaluation of new hand-held computerized systems for temporal tracking of appetite ratings. Br J Nutr 2000; 84: 405-415.

32 Blundell J, De Graaf C, Hulshof T, Jebb S, Livingstone B, Lluch A et al. Appetite control: methodological aspects of the evaluation of foods. Obes Rev 2010; 11: 251-270.

33 Jones, B, Kenward, M. Design and Analysis of Cross-Over Trials, 2nd edn. Chapman \& Hall/CRC: New York, USA 2003.

34 Bellisle F. Impact of the daily meal pattern on energy balance. Food Nutr Res 2004; 48: 114-118.

35 Reimer RR, McBurney MI. Dietary fiber modulates intestinal proglucagon messenger ribonucleic acid and postprandial secretion of glucagon-like peptide-1 and insulin in rats. Endocrinology 1996; 137: 3948-3956.

36 Sleeth ML, Thompson EL, Ford HE, Zac-Varghese SEK, Frost G. Free fatty acid receptor 2 and nutrient sensing: a proposed role for fibre, fermentable carbohydrates and short-chain fatty acids in appetite regulation. Nutr Res Rev 2010; 23: 135-145.

37 Grover GJ, Koetzner L, Wicks J, Gahler RJ, Lyon MR, Reimer RA et al. Effects of the soluble fiber complex PolyGlycopleX ${ }^{\mathbb{R}}\left(\mathrm{PGX}^{\mathbb{R}}\right)$ on glycemic control, insulin secretion, and GLP-1 levels in Zucker diabetic rats. Life Sci 2011; 88: 392-399.

38 Reimer RA, Pelletier X, Carabin IG, Lyon M, Gahler R, Parnell JA et al. Increased plasma PYY levels following supplementation with the functional fiber PolyGlycopleX in healthy adults. Eur J Clin Nutr 2010; 64: 1186-1191.

39 Le Roux CW, Batterham RL, Aylwin SJ, Patterson M, Borg CM, Wynne KJ et al. Attenuated peptide PYY release in obese subjects is associated with reduced satiety. Endocrinology 2006; 147: 3-8.
40 Battherham RL, Cohen MA, Ellis SM, Le Roux CW, Withers DJ, Frost GS et al. Inhibition of food intake in obese subjects by peptide YY3-36. New Engl J Med 2003; 349: 941-948.

41 Marciani L, Gowland PA, Spiller RC, Manoj P, Moore RJ, Young P et al. Effect of meal viscosity and nutrients on satiety, intragastric dilution, and emptying assessed by MRI. Am J Physiol Gastrointest Liver Physiol 2001; 280: G1227-G1233.

42 Maljaars PW, Peters HP, Mela DJ, Masclee AA. Ileal brake: a sensible food target for appetite control. A review. Physiol Behav 2008; 95: 271-281.

43 Van Citters GW, Lin HC. Ileal brake: neuropeptidergic control of intestinal transit. Curr Gastroenterol Rep 2006; 8: 367-373.

44 Jenkins DJ, Wolever TM, Taylor RH, Barker H, Fielden H, Baldwin JM et al. Glycemic index of foods: a physiological basis for carbohydrate exchange. Am J Clin Nutr 1981; 34: 362-366.

45 Jenkins AL, Kacinik V, Lyon M, Wolever TM. Effect of adding the novel fiber, $P G X^{\circledR}$, to commonly consumed foods on glycemic response, glycemic index and GRIP: a simple and effective strategy for reducing post prandial blood glucose levels-a randomized, controlled trial. Nutr J 2010; 22: 9:58

46 Brand-Miller JC, Atkinson FS, Gahler RJ, Kacinik V, Lyon MR, Wood S. Effects of PGX, a novel functional fibre, on acute and delayed postprandial glycemia. Eur J Clin Nutr 2010; 64: 1488-1493.

47 Arumugam V, Lee J-S, Nowal JK, Pohle RJ, Nyrop JE, Leddy J et al. A high-glycemic meal pattern elicited increased subjective appetite sensations in overweight and obese women. Appetite 2008; 50: 215-222.

48 Dewan S, Gillett A, Mugarza JA, Dovey TM, Halford JC, Wilding JP. Effects of insulin-induced hypoglycemia on energy intake and food choices at a subsequent test meal. Diabetes Metab Res Rev 2004; 20: 405-410.

49 Holt S, Brand Miller JC, Petoccz P. Interrelationship among postprandial satiety, glucose, and insulin responses and changes in subsequent food intake. Eur J Clin Nutr 1996; 50: 788-797.

50 Anderson GH, Catherine NL, Woodend DM. Inverse association between the effect of carbohydrates on blood glucose and subsequent short-term food intake in young men. Am J Clin Nutr 2002; 76: 1023-1030.

51 Bornet FRJ, Jardy-Gennetier A-E, Jacquet N, Stowell J. Glycemic response to foods: impact on satiety and long-term weight regulation. Appetite 2007; 49: 535-553.

52 Flint A, Raben A, Blundell JE, Astrup A. Reproducibility, power and validity of visual analogue scales in assessment of appetite sensations in single test meal studies. Int J Obes 2000; 24: 38-48.

53 De Graaf C. The validity of appetite ratings. Appetite 1993; 21 : 156-160.

54 De Castro J. Independence of genetic influences on body size, daily intake, and meal patterns in humans. Psychol Behav 1993; 54: 633-639.

55 Jéquier E, Tappy L. Regulation of body weight in humans. Psychol Rev 1999; 79: 451-480.

56 Herman CP, Ostovich JM, Polivy J. Effects of attentional focus on subjective hunger ratings. Appetite 1999; 33: 181-193.

57 Drewnowski A. Energy density, palatability, and satiety: implications for weight control. Nutr Rev 1998; 56: 347-353.

58 Rogers PJ, Schutz HG. Influence of palatability on subsequent hunger and food intake: a retrospective replication. Appetite 1992; 19: 155-156.

59 Womble LG, Wadden TA, Chandler JM, Martin AR. Agreement between weekly vs. daily assessment of appetite. Appetite 2003; 40: 131-135.

This work is licensed under the Creative Commons Attribution-NonCommercial-No Derivative Works 3.0 Unported License. To view a copy of this license, visit http://creativecommons.org/ licenses/by-nc-nd/3.0/ 


\section{Appendix 1}

The nutritional composition of the three-day low calorie diet

\begin{tabular}{|c|c|c|c|c|c|c|}
\hline & Quantity & Calories & Carbohydrate (g) & Fibre $(g)$ & Protein $(g)$ & Fat $(g)$ \\
\hline Day 1 & & 1004 & 156 & 7 & 55 & 16 \\
\hline Breakfast & & 244 & 38 & & 8 & 5 \\
\hline Blue Menu granola cereal & 0.5 cup & 165 & 30 & 3 & 3 & 2 \\
\hline Milk 2\% & $150 \mathrm{ml}$ & 77 & 7 & & 5 & 3 \\
\hline Tea or Coffee brewed & 1 cup & 2 & 0.7 & & 0 & 0 \\
\hline Lunch & & 340 & 58 & & 20 & 3 \\
\hline Blue Menu Chicken Bangkok & $1 \mathrm{pkg}$ & 230 & 32 & 2 & 19 & 3 \\
\hline Juice, Orange & 1 cup & 110 & 26 & & 2 & 0 \\
\hline Dinner & & 420 & 60 & & 27 & 8 \\
\hline Blue Menu Chinese Sweet \& Sour Chicken & $1 \mathrm{pkg}$ & 350 & 60 & 2 & 22 & 2 \\
\hline Marble cheese stick & 1 & 70 & 0 & & 5 & 6 \\
\hline Day 2 & & 1002 & 157 & 7 & 54 & 15 \\
\hline Breakfast & & 249 & 41 & & 9 & 2 \\
\hline Maple Brown Sugar Oatmeal & $1 \mathrm{pkg}$ & 170 & 33 & 3 & 4 & 2 \\
\hline Milk 2\% & $150 \mathrm{ml}$ & 77 & 7 & & 5 & 0 \\
\hline Tea or Coffee brewed & 1 cup & 2 & 0.7 & & 0 & 0 \\
\hline Lunch & & 333 & 57 & & 22 & 2 \\
\hline Blue Menu Ginger Glazed Chicken & $1 \mathrm{pkg}$ & 220 & 32 & 2 & 19 & 2 \\
\hline Blue Menu Multigrain Pretzels & $30 \mathrm{~g}$ & 113 & 25 & 1 & 3 & 0.3 \\
\hline Dinner & & 420 & 59 & & 23 & 11 \\
\hline $\begin{array}{l}\text { Blue Menu Thai Sweet Chili Lemon Grass } \\
\text { Chicken }\end{array}$ & $1 \mathrm{pkg}$ & 350 & 59 & 1 & 18 & 5 \\
\hline Marble cheese stick & 1 piece & 70 & 0 & & 5 & 6 \\
\hline Day 3 & & 1005 & 166 & 14 & 45 & 20 \\
\hline Breakfast & & 246 & 45 & & 9 & 5 \\
\hline Blue Menu Oatmeal Bagel & 1 & 160 & 30 & 5 & 7 & 2 \\
\hline Blue Menu Old-Fashioned Peanut Butter & $1 \mathrm{tsp}$ & 33 & 1 & 0.3 & 1 & 3 \\
\hline Tea or Coffee brewed & 1 cup & 2 & 0.7 & & 0 & 0 \\
\hline Banana, fresh, medium & $1 / 2$ & 53 & 13 & 1.5 & 1 & 0.2 \\
\hline Lunch & & 346 & 58 & & 14 & 6 \\
\hline Blue Menu Roasted Vegetable Lasagna & $1 \mathrm{pkg}$ & 240 & 33 & 3 & 12 & 6 \\
\hline Banana, fresh, medium & $1 / 2$ & 53 & 13 & 1.5 & 1 & 0.2 \\
\hline Carrots, baby, fresh & 1 cup & 53 & 12 & 2.5 & 1 & 0 \\
\hline Dinner & & 413 & 63 & & 22 & 9 \\
\hline Blue Menu Indian Butter Chicken & $1 \mathrm{pkg}$ & 370 & 52 & 2 & 21 & 9 \\
\hline Orange, medium & 0.5 & 43 & 11 & 2 & 1 & 0 \\
\hline
\end{tabular}

Abbreviations: pkg, package; tsp, teaspoon. 